\title{
Demography and habitat availability in territorial occupancy of two competing species
}

\author{
Martina Carrete, José A. Sánchez-Zapata, José F. Calvo and Russell Lande
}

\begin{abstract}
Although metapopulation dynamics have become the focus of considerable theoretical research, little attention has been paid to its role when examining the coexistence of species. When two or more species live in the same patch network, interspecific interactions may affect their dispersal, colonization and extinction rates, and it may be possible to incorporate competition affecting these parameters in metapopulation models. Here, we extend the territorial occupancy model proposed by Lande to competing species. Our model estimates an equilibrium proportion of habitat occupancy as a function of life-history parameters, dispersal behavior, habitat suitability and interspecific interactions. Moreover, it could prove to be useful as a tool in the assessment of potential management decisions. We apply the model to the golden Aquila chrysaetos and the Bonelli's eagle Hieraaetus fasciatus, two territorial raptors that coexist in the Mediterranean region, sharing food and nesting habitats. Over the last twenty years, while the golden eagle has maintained and, in some cases, increased its breeding numbers, Bonelli's eagle has suffered a marked decline, with many territories abandoned by the latter now occupied by the former. This suggests that the dynamics of these species could be influenced by interspecific competition. The model identified the relative importance of competition (stable equilibrium that allows longterm coexistence) and predicted that, when habitat overlap is slight as in the study area, intraspecific dynamics are much more important for the persistence of each species than interspecific ones. Our results suggest that the improvement of territorial bird survival and productivity are the most urgently needed actions to be undertaken in the case of the golden eagle, while for Bonelli's eagle efforts should be focused on improving territorial and non-territorial bird survival. As habitat conservation measures, the proportion of suitable exclusive habitat should be increased for both species.
\end{abstract}

M. Carrete, Dept of Applied Biology, Estación Biológica de Doñana, Avda. M. Luisa s/n, 41013, Sevilla, Spain (martina@ebd.csic.es). - J. A. Sánchez-Zapata, Dept of Applied Biology, Univ. Miguel Hernández, Ctra. de Beniel km 3.2, 33012, Orihuela, Alicante, Spain. - J. F. Calvo, Dept of Ecology and Hidrology, Univ. of Murcia, Campus de Espinardo, 30100, Murcia, Spain. - R. Lande, Dept of Biology, Univ. of California, San Diego, La Jolla, CA 92093, USA.

Research on spatially structured populations has produced both theoretical and empirical evidence for many types of structures, ranging from classical closed populations to various types of interacting subpopulations (Hanski 1999, Thomas and Kunin 1999). Models of metapopulations composed of interacting local populations (Levins 1969) have proven to be important in conservation biology (Doak 1995, Drechsler and Wissel 1997, Hanski 1999). By definition, local populations within a classical metapopulation have a substantial probability of extinction and therefore the long-term persistence of a metapopulation can only occur at regional level by a balance between local extinction and colonization (Levins 1969). An important conclu- 
sion is that a metapopulation may become extinct despite the presence of suitable habitat if the rate of local extinction exceeds that of colonization. Nevertheless, early models described extinction processes without addressing their causes (Levins 1969); this omission has recently been remedied by including demographic parameters in analytical procedures (Hanski 1999).

The metapopulation perspective involves a recognition of scales and the separation of within-patch (individual birth- and death-rates) and among-patch (patch extinction and colonization rates) dynamics. In this sense and for those cases in which the overall population viability depends more on the first one than on the latter, Lande (1987) extended and generalized a metapopulation model for application to territorial species. By identifying the unit of suitable habitat as the individual territory, he established a correspondence between local extinction and the death of the individuals inhabiting a territory, as well as between colonization and individual dispersal and settlement in a suitable, unoccupied territory. This little used model could be employed to predict the effects of future habitat loss or demographic constraints on population persistence (Lande 1988, Noon and McKelvey 1996, Carrete et al. 2002a).

Metapopulation models have become the focus of considerable theoretical research. However, less attention has been paid to the role of metapopulation structures in the coexistence of competitor species. When two or more species live in the same patch network, interspecific interactions may affect dispersal, colonization and extinction rates, and so competition affecting one of these parameters could be incorporated into metapopulation models (Hanski 1983, 1999, Nee and May 1992, Tilman 1994). For two territorial competing species, Lande's model could be extended by incorporating a term that constrains the occupation rate of each territory by the other species. This new model, developed for the first time in this paper, assumes that interspecific competition exists at the moment a territory is occupied and that no displacement occurs after the establishment of a territorial pair. Therefore, only unoccupied patches (i.e. territories) are available for colonization.

To illustrate the model and to assess its usefulness, we applied it to two territorial competing raptors: the golden eagle and the Bonelli's eagle. The distributions of these two monogamous, long-lived species coincide in the Mediterranean area (Cramp and Simmons 1980, del Hoyo et al. 1994), where they show a considerable overlap in their diets and nesting habitats (both are cliff-nesting raptors with a $90.5 \%$ of diet overlap in our study area, Sánchez-Zapata et al. 1995). The population dynamics of these species have followed markedly different trends over the last twenty years. Whilst the golden eagle has maintained and, in some cases, increased its breeding numbers (Díaz et al. 1996), Bonelli's eagle has suffered a notable decline over all of its European range (Rocamora 1994, Real and Mañosa 1997). Consequently, many territories abandoned by Bonelli's eagles have been occupied by golden eagles, suggesting that colonization processes could be influenced by competition (Jordano 1981, Fernández and Insausti 1990, Sánchez-Zapata 1997, Rico et al. 1999). Moreover, as the golden eagle is bigger than Bonelli's eagle (2840-6665 g vs 1600-2400 g, respectively; del Hoyo et al. 1994), it has been suggested that golden eagle could be a better competitor in areas where the two species coexist (Gil 1994, Gil-Sánchez et al. 2004).

The aims of this paper are (a) to extend Lande's model to two territorial competing species, (b) to assess the incidence of interspecific competition in the population dynamics of the golden eagle and the Bonelli's eagle, and (c) to predict the effects of changes in habitat availability and demographic parameters on the conservation of these species.

\section{Methods}

\section{The model}

The model assumes that an area may hold a finite number of potentially suitable (occupied and unoccupied) and unsuitable breeding territories. Among this total number of potential territories, there are two sets that are exclusively suitable for only one of the two species and another set that is equally suitable for both species (Fig. 1). Thus, $1-\mathrm{h}$ corresponds with the unsuitable habitat for both species, $\mathrm{h}_{\mathrm{i}}$ to the suitable breeding habitat for species $\mathrm{i}, \mathrm{h}_{\mathrm{j}}$ to the suitable habitat for species $\mathrm{j}$ and $\mathrm{h}_{\mathrm{ij}}$ to the overlapping suitable habitat, with $h_{i}-h_{i j}$ and $h_{j}-h_{i j}$ being the exclusive suitable habitat for species $i$ and $j$, respectively. We assume that

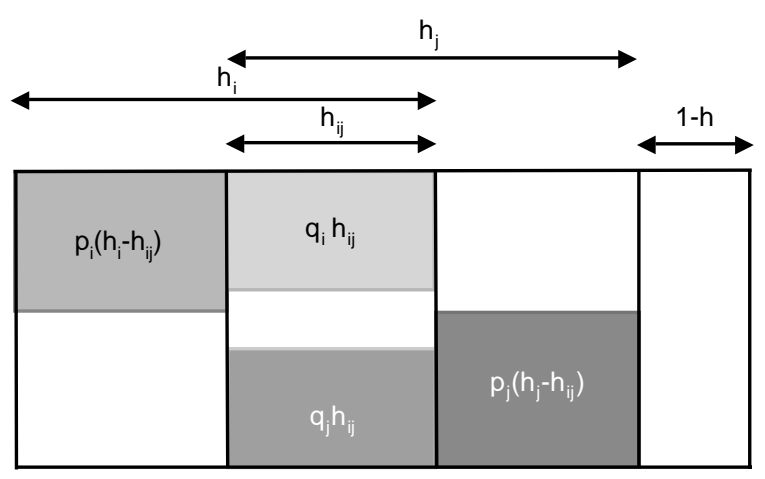

Fig. 1. Scheme showing the proportions of suitable habitat for species $\mathrm{i}\left(\mathrm{h}_{\mathrm{i}}\right)$ and $\mathrm{j}\left(\mathrm{h}_{\mathrm{j}}\right)$, the proportion of overlapping habitat $\left(\mathrm{h}_{\mathrm{ij}}\right)$ and the proportion of unsuitable habitat for both species $(1-h)$. The proportions of occupancy for both species in the exclusive ( $\mathrm{p}_{\mathrm{i}}$ and $\mathrm{p}_{\mathrm{j}}$, respectively) and in the overlapping $\left(\mathrm{q}_{\mathrm{i}}\right.$ and $\mathrm{q}_{\mathrm{j}}$, respectively) habitat have been also included. 
suitable exclusive and overlap territories are randomly distributed across the region, at least on a scale of the typical individual dispersal distance. This model differs from previous ones of its type by ignoring all habitat that is not potentially suitable for breeding, because potential breeding sites for eagles are clumped in mountainous areas which therefore constitute the region under consideration.

The territorial occupancy model for two competing species uses the equilibrium occupancy of suitable habitat by females in the exclusive $\left(p_{i}\right.$ and $p_{j}$ ) and in the overlapping $\left(\mathrm{q}_{\mathrm{i}}\right.$ and $\mathrm{q}_{\mathrm{j}}$ ) habitat as well as the proportion of the potential habitat that is suitable $\left(\mathrm{h}_{\mathrm{i}}\right.$, $h_{j}$ and $h_{i j}$ ) to estimate the demographic potential of each population $\left(\mathrm{k}_{\mathrm{i}}\right.$ and $\left.\mathrm{k}_{\mathrm{j}}\right)$, i.e. the maximum occupancy of territories at equilibrium in a completely suitable habitat. Therefore, it allows us to predict the effects of environmental and demographic changes (changes in $\mathrm{h}$ and $\mathrm{k}$, respectively) on interspecific competition and coexistence of the two species.

If we assume that the expected rate of production of female offspring by a mature female (b) and adult survivorship $\left(\mathrm{s}_{\mathrm{t}}\right)$ are independent of age after the first reproduction at age $\alpha$, then the mean lifetime production of female offspring by a female, $\mathrm{R}_{0}$, is:

$\mathrm{R}_{0}=\mathrm{s}_{0} \mathrm{~s}_{\mathrm{n}} \sum_{\mathrm{x}=\alpha}^{\infty} \mathrm{s}_{\mathrm{t}}^{\mathrm{x}-\alpha}=\mathrm{s}_{0} \mathrm{~s}_{\mathrm{n}} \mathrm{b} /\left(1-\mathrm{s}_{\mathrm{t}}\right)$

where $s_{0}$ and $s_{n}$ are survival during the post-fledgling dependence period and during the non-territorial dispersal period, respectively (below).

The probability that a juvenile of species i during obligatorily dispersal, as occurs in many territorial species, succeeds in finding a suitable unoccupied territory in $\mathrm{m}$ searches is:

$s_{n}=1-\left[1-h_{i}+p_{i}\left(h_{i}-h_{i j}\right)+q_{i j} h_{i j}+q_{j j} h_{i j}\right]^{m}$

where $1-h_{i}$ represents the unsuitable habitat, $p_{i}\left(h_{i}-h_{i j}\right)$ and $\mathrm{q}_{\mathrm{i}} \mathrm{h}_{\mathrm{ij}}$ are the proportion of exclusive habitat and the proportion of overlapping habitat unavailable because of the presence of a conspecific bird, and $\mathrm{q}_{\mathrm{j}} \mathrm{h}_{\mathrm{ij}}$ represents interspecific competition in the suitable overlapping habitat, assuming that competition occurs during the initial occupancy of a territory and given that a territory is available for occupation only if it is empty (Fig. 1).

When the population is at a demographic equilibrium (i.e. there is a constant population size and age structure) $\mathrm{R}_{0}=1$ or

$\left[1-\left[1-h_{i}+p_{i}\left(h_{i}-h_{i j}\right)+\left(q_{i}+q_{j}\right) h_{i j}\right]^{m i}\right] R_{0 i}^{\prime}=1$

where $\mathrm{R}_{0}^{\prime}=\mathrm{s}_{0} \mathrm{~b} /\left(1-\mathrm{s}_{\mathrm{t}}\right)$ is the mean lifetime production of female offspring by a female, provided that the mother finds a territory. Following Lande (1987), we define $k_{i}$ as the demographic potential of species $i$ as $k_{i}=\left(1-1 / R_{0 i}^{\prime}\right)^{1 / m i}$. Equation 3 then becomes: $1-\mathrm{h}_{\mathrm{i}}+\mathrm{p}_{\mathrm{i}}\left(\mathrm{h}_{\mathrm{i}}-\mathrm{h}_{\mathrm{ij}}\right)+\left(\mathrm{q}_{\mathrm{i}}+\mathrm{q}_{\mathrm{j}}\right) \mathrm{h}_{\mathrm{ij}}=\mathrm{k}_{\mathrm{i}}$

Because we assume that suitable exclusive and overlapping habitat is randomly distributed and that the overlapping habitat is equally suitable for both species, it follows that in the overlapping habitat, the proportion of territories occupied by species $i$ and $j$ are respectively:

$\mathrm{q}_{\mathrm{i}}=\mathrm{p}_{\mathrm{i}}\left(1-\mathrm{q}_{\mathrm{i}}\right)$ and $\mathrm{q}_{\mathrm{j}}=\mathrm{p}_{\mathrm{j}}\left(1-\mathrm{q}_{\mathrm{i}}\right)$

so that

$\mathrm{q}_{\mathrm{i}}=\left(\mathrm{p}_{\mathrm{i}}-\mathrm{p}_{\mathrm{i}} \mathrm{p}_{\mathrm{j}}\right) /\left(1-\mathrm{p}_{\mathrm{i}} \mathrm{p}_{\mathrm{j}}\right)$ and $\mathrm{q}_{\mathrm{i}}=\left(\mathrm{p}_{\mathrm{j}}-\mathrm{p}_{\mathrm{i}} \mathrm{p}_{\mathrm{j}}\right) /\left(1-\mathrm{p}_{\mathrm{i}} \mathrm{p}_{\mathrm{j}}\right)$

Substituting in Eq. 4,

$1-h_{i}+p_{i}\left(h_{i}-h_{i j}\right)+\left[\left(p_{i}+p_{j}-2 p_{i} p_{j}\right) /\left(1-p_{i} p_{j}\right)\right] h_{i j}=k_{i}$

This equation can be used to calculate $\mathrm{k}_{\mathrm{i}}$ (and $\mathrm{k}_{\mathrm{j}}$ ) from current estimates of $p_{i}, p_{j}, h_{i}, h_{j}$ and $h_{i j}$. Solving Eq. 7 for $p_{i}$ we obtain the equilibrium isocline describing the proportion of occupancy of exclusive habitat expected for species $i$ at equilibrium for any given value of $p_{j}$. We also use this equation to calculate the intersections between the equilibrium isocline representing each species and the $p_{i}$ and $p_{j}$ axes:

$\mathrm{p}_{\mathrm{i}}= \begin{cases}\left(\mathrm{k}_{\mathrm{i}}-1+\mathrm{h}_{\mathrm{i}}\right) / \mathrm{h}_{\mathrm{j}} & \text { for } \mathrm{p}_{\mathrm{i}}=0 \\ 0 & \text { for } \mathrm{p}_{\mathrm{j}}=\left(\mathrm{k}_{\mathrm{i}}-1+\mathrm{h}_{\mathrm{i}}\right) / \mathrm{h}_{\mathrm{ij}}\end{cases}$

The proportions of occupancy of exclusive habitat for both species can be illustrated graphically as in the Lotka-Volterra model (Fig. 2; Begon et al. 1988) to recognize the outcome of interspecific competition. The possible outcomes, assuming at most a single intersection, are: a) if $\mathrm{I}_{\mathrm{ii}}>\mathrm{I}_{\mathrm{ji}}, \mathrm{I}_{\mathrm{ij}}>\mathrm{I}_{\mathrm{jj}}$, species i displaces species $\mathrm{j}$; b) if $I_{j i}>I_{i i}, I_{j j}>I_{i j}$, species $j$ displaces species $i$, and c) if $\mathrm{I}_{\mathrm{ji}}>\mathrm{I}_{\mathrm{ii}}, \mathrm{I}_{\mathrm{ij}}>\mathrm{I}_{\mathrm{jj}}$, both species can coexist in the long-term. Here, $I_{\mathrm{ii}}$ is the intersection between the isocline representing species $i$ and the $p_{i}$ axes, $I_{i j}$ is the intersection between the isocline representing species $j$ and the $p_{i}$ axes, $\mathrm{I}_{\mathrm{ji}}$ is the intersection between the isocline representing species $i$ and the $p_{j}$ axes, and $I_{j j}$ is the intersection between the isocline representing species $j$ and the $p_{j}$ axes. Our model does not allow the existence of an unstable equilibrium where the outcome of competition depends on the initial population sizes. Here, we present the mathematical demonstration of this point. Following Lande (1987, 1988), we denoted the stable single-species equilibria as $\mathrm{p}_{\mathrm{i}}^{1}=1-\left(1-\mathrm{k}_{\mathrm{i}}\right) / \mathrm{h}_{\mathrm{i}}$ and $\mathrm{p}_{\mathrm{j}}^{1}=1-\left(1-\mathrm{k}_{\mathrm{j}}\right) / \mathrm{h}_{\mathrm{j}}$. From Eq. 8 the intercepts of the equilibrium isoclines with the axes are $I_{i i}=p_{i}^{1}, \quad I_{j j}=p_{j}^{1}, \quad I_{j i}=$ $\left(h_{i} / h_{i j}\right) p_{i}^{1}$ and $I_{i j}=\left(h_{j} / h_{i j}\right) p_{j}^{1}$. The conditions for an unstable two-species equilibrium then becomes $\mathrm{p}_{\mathrm{i}}^{1}>$ $\left(h_{j} / h_{i j}\right) p_{j}^{1}$ and $p_{j}^{1}>\left(h_{i} / h_{i j}\right) p_{i}^{1}$. Multiplying both inequalities by $h_{i j}$ and adding them yields $\left(h_{i}-h_{i j}\right) p_{i}^{1}+\left(h_{j}-h_{i j}\right)$ $\mathrm{p}_{\mathrm{j}}^{1}<0$. But all of the quantities on the left side must be 

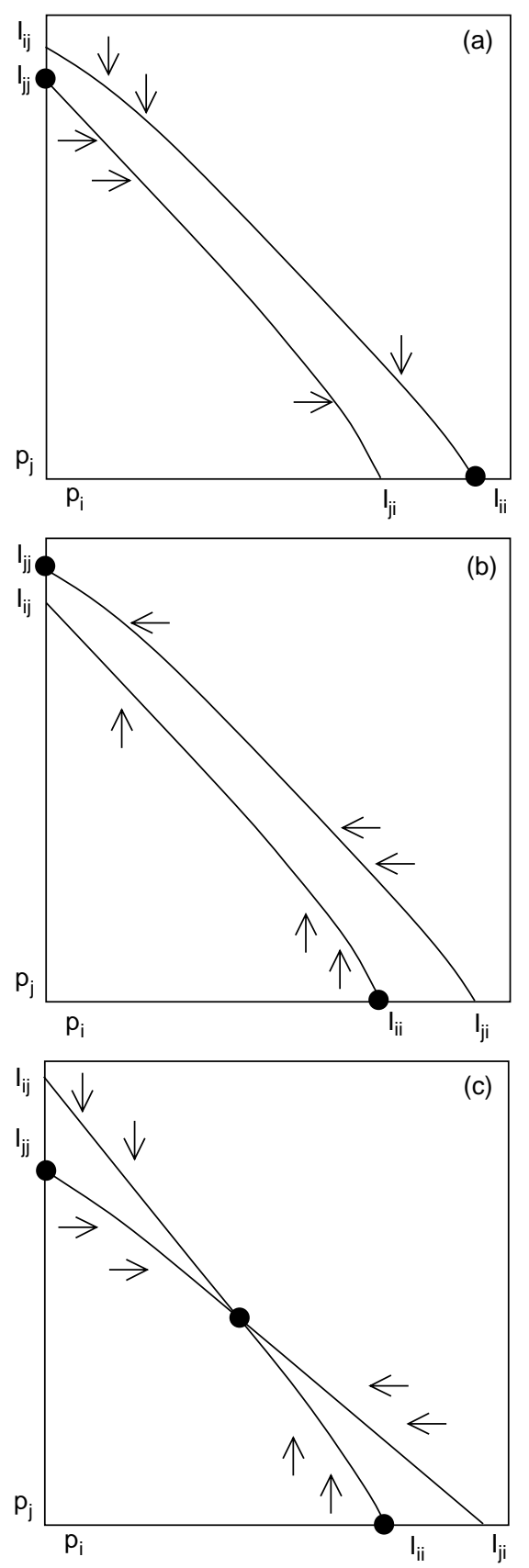

Fig. 2. Three possible outcomes for the competition between two territorial species: (a) $I_{i i}>I_{j i}, I_{i j}>I_{j i}$, and species i displaces species j; (b) $I_{j i}>I_{i i}, I_{j j}>I_{i j}$, species $j$ displaces species $i$, and (c) $\mathrm{I}_{\mathrm{ji}}>\mathrm{I}_{\mathrm{ii}}, \mathrm{I}_{\mathrm{ij}}>\mathrm{I}_{\mathrm{jj}}$, both species can coexist in the long-term. $\mathrm{p}_{\mathrm{i}}$ : proportion of occupancy of exclusive habitat for species $\mathrm{i}$; $p_{j}$ : proportion of occupancy of exclusive habitat for species $j ; I_{i i}$ : intersection between equilibrium isocline for species $\mathrm{i}$ and the axis $p_{i} ; I_{i j}$ : intersection between equilibrium isocline for species $i$ and the axis $p_{\mathrm{j}} ; \mathrm{I}_{\mathrm{ji}}$ : intersection between equilibrium isocline for species $\mathrm{j}$ and the axis $\mathrm{p}_{\mathrm{i}} ; \mathrm{I}_{\mathrm{jj}}$ : intersection between equilibrium isocline for species $\mathrm{j}$ and the axis $\mathrm{p}_{\mathrm{j}}$. Dark points represent the one-species ( $\mathrm{a}$ and $\mathrm{b}$ ) and the two-species equilibria (c). Representation of the model is partially taken from Hutchinson (1981). non-negative, so the last inequality is impossible. Therefore, an unstable two-species equilibrium can not occur.

\section{Model parameters and application}

\section{Study area and species populations}

Our study area comprises the province of Murcia (southeast Spain), an $11317 \mathrm{~km}^{2}$ area with a semi-arid Mediterranean climate (for a description of the study area, see Carrete et al. 2000). Although this region held a high density of Bonelli's eagles in the 1980's, populations have declined considerably since then owing to direct human persecution and electrocution and collision with power lines (Sánchez-Zapata 1997, Real et al. 2001). On the other hand, the golden eagle seems to have maintained its population numbers over the same period, occupying a set of territories that previously belonged to Bonelli's eagles (Sánchez-Zapata 1997, Carrete et al. 2002b).

\section{i. Habitat availability}

To estimate the number of potential territories for cliffnesting eagles in the study area, we defined a territory or breeding area as any area with both cliffs and hunting habitat in the surrounding (mainly open areas, Carrete et al. 2000, 2002b) where nests of the studied species have ever been found. The proportions of the region that are exclusively suitable for each species (i.e., $\mathrm{h}_{\mathrm{G}}-\mathrm{h}_{\mathrm{GB}}$ and $h_{B}-h_{B G}$, for golden and Bonelli's eagles, respectively) were obtained as the proportions of territories ever occupied by each species during the period of population stability, i.e. when $R_{0}=1$ (golden eagle: 1997-2001 and Bonelli's eagle: 1990-1998), out of the total number of 110 territories known for cliff-nesting eagles in the study area. Overlapping habitat $\left(\mathrm{h}_{\mathrm{GB}}=\mathrm{h}_{\mathrm{BG}}\right)$ was estimated as the proportion of territories that have been alternatively occupied by both species since 1983. The proportions of occupancy $\mathrm{p}_{\mathrm{G}}$ and $\mathrm{p}_{\mathrm{B}}$ for golden and Bonelli's eagles, respectively, were obtained as the proportion of suitable exclusive territories $\left(\mathrm{h}_{\mathrm{G}}-\mathrm{h}_{\mathrm{GB}}\right.$ or $\left.\mathrm{h}_{\mathrm{B}}-\mathrm{h}_{\mathrm{GB}}\right)$ that were occupied by each species during the period of stability.

Assuming that the probability of colonizing a suitable unoccupied territory by any species is constant across the habitat (i.e. for each species there are no differences between territories included in the exclusive or overlapping habitat; Carrete et al. 2002 unpubl.), we modeled interspecific competition by only using $\mathrm{p}_{\mathrm{G}}$ and $\mathrm{p}_{\mathrm{B}}$ (Eq. 7, 8). Assuming population stability for both species, we calculated $\mathrm{k}_{\mathrm{B}}$ and $\mathrm{k}_{\mathrm{G}}$ from current estimates of $\mathrm{p}_{\mathrm{B}}, \mathrm{p}_{\mathrm{G}}$, $h_{B}, h_{G}$ and $h_{G B}$ (Eq. 7). These values were then used to estimate $m_{G}$ and $m_{B}$ the search ability of golden eagle and Bonelli's eagle, respectively. 


\section{ii. Demographic parameters}

Populations of golden and Bonelli's eagles were surveyed from 1997 to 2001 and from 1983 to 2001, respectively. All potential breeding areas for both species were visited during the breeding season. Breeding territories were located by observing territorial activity, courtship, brood-rearing activity, young birds or any other conspicuous behavior (Carrete et al. 2002b).

Populations were considered to be organized into three stage classes: juveniles during post-fledging dependence period, non-territorial independized birds (juveniles, sub-adult and adult birds without a territory), and territorial birds (eagles occupying a breeding site, mainly adults). This is a useful simplification because it represents the successive life stages of an eagle from leaving the nest until occupying a breeding territory, and it corresponds better to mortality probability than the exact age of each individual (Real et al. 2001).

The annual survival rate for territorial birds $\left(s_{t}\right)$ was calculated as the proportion of birds present in the population at the start of the breeding season that was still present in the population at the start of the following breeding season. A bird was considered to be dead if it had disappeared from its breeding territory from one year to the next or if it had been replaced by another bird. Differential plumage color during the first four years of life allows the rate of replacement of adults by birds under four years old to be assessed in both species (Forsman 1999); thus, we were able to estimate the maximum territorial survival rate (Carrete et al. 2002a). No observations of birds and the absence of arranged nests or droppings on perches were taken as evidence for the disappearance of a pair. When a pair was not recorded in its traditional territory, we searched within a radius of several kilometers for suitable breeding habitats to exclude the possibility of a pair having moved to a new breeding site. Because no information exists for the European populations of the golden eagle, we used 0.78 as a survival rate during the post-fledging dependence period $\left(\mathrm{s}_{0}\right)$ for both species, a value obtained for Bonelli's eagles in the Mediterranean area (Real and Mañosa 1997). Non-territorial survival rate $\left(s_{n}\right)$ was obtained by equating this rate with the probability of successful juvenile dispersal (Eq. 2; Noon and McKelvey 1996, Carrete et al. 2002a). Productivity (P) was calculated as the annual number of young fledged per territorial pair. Demographic analyses are usually formulated exclusively in terms of females so, assuming an overall 1:1 offspring sex ratio (Real and Mañosa 1997), fecundity (b) was calculated as $\mathrm{P} / 2$.

\section{iii. Perturbation analysis}

We used the model as follows to analyze alternative biological situations (Fig. 3):

Perturbations in habitat availability. Although these species seem to have similar habitat requirements in the study area (Carrete 2002), we can use the model to investigate situations that may arise in different parts of their distribution ranges.

a) Increases in the proportion of suitable habitat for one species while decrease the suitable habitat of its competitor. Maintaining the total number of territories and a low habitat overlap $\left(\mathrm{h}_{\mathrm{ij}}\right)$, we progressively increased the number of suitable territories for one species in detriment of the other. We considered that one species (i or j) has an exclusive set of territories composed only by their occupied territories, while the habitat availability of the other species is increased by adding the vacant territories of its competitor (Fig. 3a).

b) Increases in the proportion of suitable habitat for one species while the suitable habitat for its competitor is maintained. We considered that the suitable habitat of each species could be increased without changing the number of suitable territories of the competitor. Thus, we sequentially added those territories which are not suitable for any species to each one, while we maintained the exclusive territories of the competitor (Fig. 3b).

c) Increases in suitable overlapping habitat. Finally, we increased the proportion of habitat overlap by reducing the habitat availability of one species $\left(h_{G}\right.$ and $h_{B}$, respectively) while we maintained the habitat availability of its competitor (Fig. 3c).

Perturbations in demographic parameters. The model also allows us to test if changes in demography can alter the coexistence of these two species as well as to identify the most important parameters for population persistence.

d) Territorial bird survivorship. Among long lived raptors, adult survival has been mentioned as one of the most important factors influencing population growth rates (Newton 1979). Using as maximum $s_{t}=0.96$, a value obtained in a wild population of Bonelli's eagle in Europe (Real and Mañosa 1997), and considering that it represents an increment of approximately $8 \%$ of the current value of this parameter in the Bonelli's eagle population studied, we fixed this percentage as a maximum to progressively increase and decrease the territorial survival of both species (Fig. 3d).

e) Productivity. We increased productivity by using an average of 1.4 fledging produced per territorial pair, since this figure is near the maximum that could be obtained by these large eagles (Real and Mañosa 1997, Watson 1997). To make changes comparable, and considering that 1.4 fledging produced per territorial pair represents an increment of $19 \%$ in the present productivity of the Bonelli's eagle population, we used this percentage of change as a maximum for both species (Fig. 3e).

f) Non-territorial bird survivorship. Among territorial species, colonization processes strongly depend on the dispersal capacity of non-territorial birds. In our model, this situation is represented by the parameter $\mathrm{m}$, i.e. the 


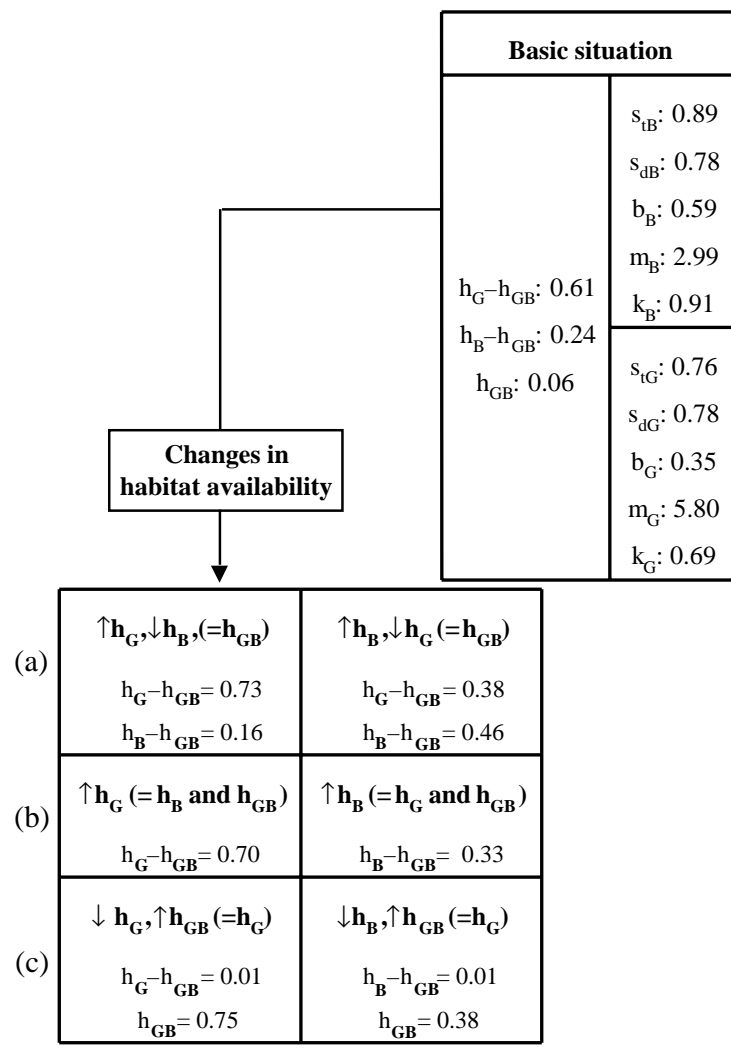

search ability of dispersing birds. For perturbations, we employed the double (increases) and the half (decreases) of the $\mathrm{m}$ values obtained from each population in the study area (Fig. 3f).

g) Fledgling survivorship. Considering that the highest value that could be expected for $\mathrm{s}_{\mathrm{di}}$ is 1 , we used this value as a maximum for both species (Fig. $3 \mathrm{~g}$ ). The minimum for both species was 0.56 , which represents $28 \%$ of change with respect to the current values of this parameter.

\section{Results}

The golden eagle population remained stable during the period 1997-2001 (population growth rate, $\lambda=0.99$ ), while the Bonelli's eagle declined from 1983 to 1990, the year in which this population stabilized (population growth rate, $\lambda=0.99$ ). Table 1 summarizes the demographic parameters for the period during which both populations stabilized, as well as the model's parameters. We surveyed all the potential 110 breeding territories of
Fig. 3. Summary of the parameters used for perturbations in habitat availability and demographic parameters. Except for Fig. 3b and 3c, $1-\mathrm{h}=0.09$ (10 territories). (d)

(e)

(f)

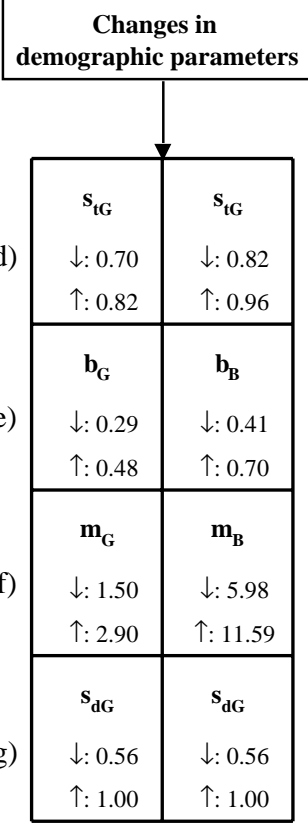

cliff-nesting eagles. We considered that 67 territories remained suitable for occupation by golden eagles, while for Bonelli's eagles there were 26. As suitable overlapping habitat, we conservatively considered seven territories, which corresponded to those abandoned by Bonelli's eagles and subsequently colonized by golden eagles (Table 1; Carrete et al. 2002b).

\section{Model application}

Figure 4 shows the proportion of territories occupied by each species assuming that, although both species compete for a fraction of these territories, a set of mutually exclusive areas also exists and that the probability of occupancy is the same for exclusive and shared territories. Both lines intersect at a point of equilibrium which approximately corresponds, when we considered the occupancy as a proportion of the total number of territories to allow comparisons between species, to $\mathrm{p}_{\mathrm{G}}=0.52$ and $\mathrm{p}_{\mathrm{B}}=0.69$. As in the situation exposed in Fig. $2 \mathrm{c}, \mathrm{I}_{\mathrm{gb}}>\mathrm{I}_{\mathrm{bb}}$ and $\mathrm{I}_{\mathrm{bg}}>\mathrm{I}_{\mathrm{gg}}$, meaning that intraspecific 
Table 1. Basic demographic parameters and estimates of demographic potential of golden (1997-2001) and Bonelli’s eagles (19901998).

\begin{tabular}{|c|c|c|}
\hline Parameters & $\begin{array}{l}\text { Golden } \\
\text { eagle }\end{array}$ & $\begin{array}{l}\text { Bonelli's } \\
\text { eagle }\end{array}$ \\
\hline Fledging survival probability $\left(\mathrm{s}_{0}\right)$ & 0.78 & 0.78 \\
\hline Non-territorial survival probability $\left(\mathrm{s}_{\mathrm{n}}\right)$ & 0.81 & 0.11 \\
\hline Annual territorial survival probability $\left(\mathrm{s}_{\mathrm{t}}\right)$ & 0.76 & 0.89 \\
\hline Fecundity (b) & 0.35 & 0.59 \\
\hline $\mathrm{R}_{0}^{\prime}$ & 1.14 & 4.18 \\
\hline Potentially suitable and unsuitable habitat (number of territories) & 110 & 110 \\
\hline Exclusive habitat, $\mathrm{h}_{\mathrm{i}}-\mathrm{h}_{\mathrm{ij}}$ (number of territories) & $\mathrm{h}_{\mathrm{G}}=0.61(67)$ & $\mathrm{h}_{\mathrm{B}}=0.24(26)$ \\
\hline Overlapping habitat, $\mathrm{h}_{\mathrm{ij}}$ (number of territories) & \multicolumn{2}{|c|}{$\mathrm{h}_{\mathrm{GB}}=0.06(7)$} \\
\hline Exclusive habitat occupied (number of territories) & $\mathrm{P}_{\mathrm{G}}=0.52(35)$ & $\mathrm{p}_{\mathrm{B}}=0.69(18)$ \\
\hline Demographic potential $\left(\mathrm{k} \pm \mathrm{s}_{\mathrm{k}}^{2}\right)$ & $0.69( \pm 0.0001)$ & $0.91( \pm 0.001)$ \\
\hline Minimum number of exclusive territories & 21 & 2 \\
\hline
\end{tabular}

dynamics are more important for determining the proportion of territories occupied by each species than interspecific dynamics. Consequently, the expected competition outcome is a stable equilibrium between both species when habitat overlap is low.

\section{Perturbations analysis}

Perturbations were run by progressively increasing and decreasing each parameter. This approach can be used to detect, for example, when a population would become extinct.

\section{Perturbations in habitat availability}

Changing suitable habitat produced two main scenarios: a stable equilibrium that allows the long term persistence of both species (Fig. 5a, b), or the extinction of one

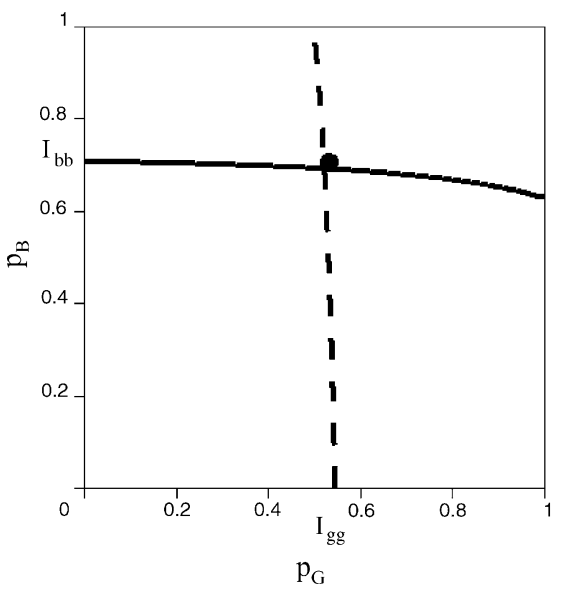

Fig. 4. Proportion of occupancy of golden (dashed line; $p_{G}$ ) and Bonelli's (continued line; $\mathrm{p}_{\mathrm{B}}$ ) eagles. The graph corresponds with the situation (c) of Fig. 1, i.e. a stable equilibrium that allows coexistence. Dark point represents the situation observed during 2001, corresponding with the two-species equilibrium. species while the other persists (Fig. 5c). Increments in the proportion of suitable habitat for one species, with (Fig. 5a) or without (Fig. 5b) reduction in the exclusive habitat of its competitor, lead to changes in the lines with respect to the basic model, but maintain the relationship $I_{g b}>I_{b b}$ and $I_{b g}>I_{g g}$ and therefore the output of the competition process. Increments in habitat availability for one species in detriment of the other (Fig. 5a) results in an increase of the number of territories occupied by the species benefited by management, while reduce the proportion of occupancy of the competitor whose habitat has been reduced. However, when increments in the habitat of one species do not change the habitat availability of its competitor, both species benefit because the species favored by management increases the proportion of occupancy while the other remains unchanged (Fig. 5b). But when the proportion of suitable overlapping habitat increased while the exclusive habitat of one species was reduced, the situation changed with respect to the basic model, and the species whose habitat had been reduced became extinct (Fig. 5c).

\section{Perturbations in demographic parameters}

Displacement in the equilibrium point occurred primarily for the species with demographic parameters perturbed (Fig. 5d-g); however, the responses to perturbations were disproportionately large for certain parameters. The equilibrium golden eagle population moved markedly when territorial bird survivorship $s_{t}$ (Fig. 5d), productivity (expressed as female fecundity b, Fig. 5e) and survival during the dependence period (Fig. 5g), were changed, but moved slightly when we changed non territorial bird survivorship $s_{n}$ through search ability $\mathrm{m}$ (Fig. 5f). For Bonelli's eagle population, changes in territorial bird survivorship $\mathrm{s}_{\mathrm{t}}$ (Fig. 5d) and search ability $\mathrm{m}$ (Fig. 5f) had the most important influence on the proportion of occupancy predicted, while changes in productivity (Fig. 5e) and survival during the dependence period (Fig. 5g) were less 
(a)

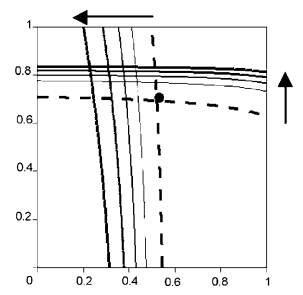

(b)

$\stackrel{\infty}{2}$

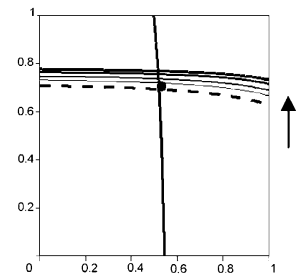

(c)

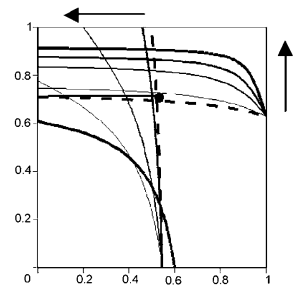

(d)

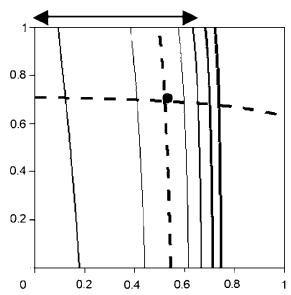

(e)

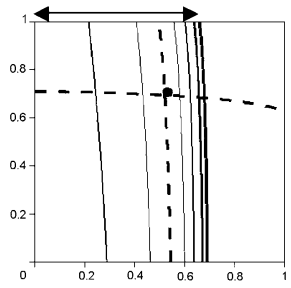

(f)

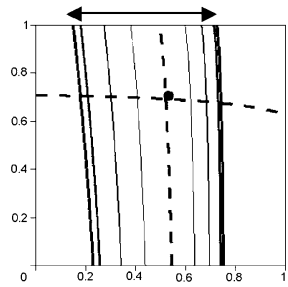

(g)

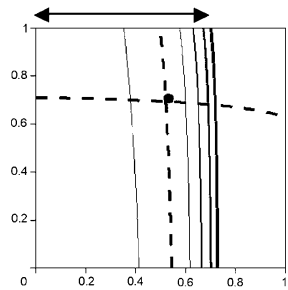

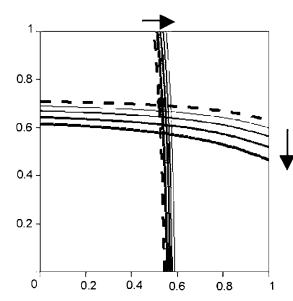
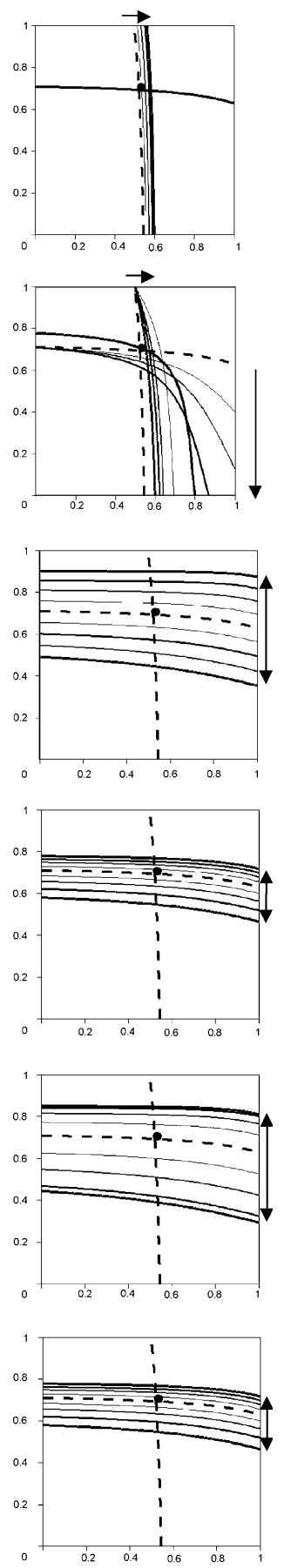

Fig. 5. Proportion of occupancy of golden $\left(\mathrm{p}_{\mathrm{G}}\right.$; $\mathrm{x}$-axes) and Bonelli's ( $\mathrm{p}_{\mathrm{B}}$; $\mathrm{y}$-axes) eagles under different scenarios of habitat availability and demography: (a) increases in the proportion of suitable habitat for each species, (b) increases in the proportion of suitable habitat for both species, (c) increases in suitable overlapping habitat, (d) increases in territorial bird survivorship, (e) increases in productivity, (f) increases in non-territorial bird survivorship (representing by $\mathrm{m}$, the search ability of dispersing birds), and g) increases in survival during dependence period. Dark points represent the situation observed during 2001, corresponding with the two-species

equilibrium; dashed lines show the basic situation (Fig. 3), while continuous lines represent the situation after the application of management actions. 
important. Except for non territorial bird survivorship $\mathrm{s}_{\mathrm{n}}$, decreases in all the other demographic parameters involved the extinction of the golden eagle population.

\section{Discussion}

The territorial occupancy model developed by Lande (1987), extended here to include two competing species, represents a useful tool for evaluating how equilibrium breeding numbers could be affected by changes in habitat availability, demographic parameters, dispersal behavior and interspecific competition (Lande 1987, Moilanen and Hanski 1995, Hanski 1999). Its application shows that increases in the exclusive suitable habitat of each species is the best option to maintain viable populations of territorial competitors in a same area, given that it reduces competition for territories. Increases in habitat overlap by reducing the exclusive habitat available for one species strongly affected the outcome of competition, resulting in extinction of the species for which exclusive habitat had been eliminated. Changes in the demographic parameters of one of the populations when habitat overlap between competitors was slight, however, only changed the equilibrium breeding numbers.

Traditional explanations for range limits in the distributions of species have always emphasized variation along gradients in local demographic processes (Wilson et al. 1996). However, our model strongly supports the hypothesis of Carter and Prince (1981) which proposed that the limits to the distribution of species may also arise from metapopulation dynamics. For species whose persistence depend upon a balance between colonization and local extinction, they proposed three distinct causal routes to explain range limits: (a) gradients in local extinction rates (lower quality habitat available at the periphery), (b) gradients in local colonization rates (the matrix of habitat separating patches is more hostile to dispersal, and/or occupied patches at the periphery produce fewer dispersing individuals), and (c) gradients in habitat availability (less suitable habitat available at the periphery). Among these scenarios, the gradient in habitat availability produces the most fragmented edge (Holt and Keitt 2000) and, for the ranges of two species, implies areas of coexistence, where competition depends on the degree of resource overlap (Hutchinson 1981). The more overlap (in our case, the proportion of territories that could be potentially colonized by both species) the higher the probability that the species with a less exclusive habitat becomes extinct or more vulnerable to stochastic processes (Ives 1995), as exemplified in Fig. 5c. Outside overlap areas, only one of the species persisted because habitat availability for its competitor disappeared or was extremely small, as shown in Fig. 5a.
One of the most interesting applications of modeling is to predict the population trends of rare and endangered species (Doak 1995, Hiraldo et al. 1996, Little et al. 1996, Real and Mañosa 1997, Franklin et al. 2000, Carrete et al. 2002a, Lande et al. 2003, McCarthy et al. 2003). Models are frequently used as tools for choosing management actions aimed at increasing the chance of population persistence (Martien et al. 1999, Woodworth 1999, Burgman 2000). However, it is important to bear in mind that models are a simplification of a more complex natural reality and that demographic parameters estimated from wild populations are not exact. The territorial occupancy model has been previously applied to single territorial species, such as the spotted owl Strix occidentalis caurina (Lande 1988) or the Bonelli's eagle (Carrete et al. 2002a). However, to our knowledge, this is the first time the model has been extended to assess the potential role of interspecific competition between two territorial competing species. One of the most interesting conclusions obtained from this two-species model was that intraspecific processes are more important than interspecific ones as limiting factors for territorial occupation of the two eagle species considered here, which compete for food and nesting sites. This result has important implications for their populations, since contrary to the supposed competition exerted by the golden eagle on Bonelli's eagle (Cramp and Simmons 1980, del Hoyo et al. 1994, Gil-Sánchez et al. 2004), such competition seems to be a secondary factor in the decline of the latter, smaller species (Carrete et al. 2002b).

Although there is a certain degree of habitat overlap between both eagles (Carrete 2002), the outcome of competition in our model was a stable equilibrium that allowed coexistence, with a proportion of occupancy determined by the intrinsic population dynamics of each species. This does not contradict the fact that many abandoned territories of Bonelli's eagle have been occupied by golden eagles, both in our study area and elsewhere (Fernández and Insausti 1990, Carrete et al. 2002b), but suggests that these territories may correspond to the suitable overlap habitat. Perturbation analysis suggests that conservation strategies should be simultaneously focused on demography and habitat management. Improvements in the different demographic parameters always increase the proportion of territories occupied by each species, until a maximum imposed by habitat availability. Thus, if habitat is simultaneously managed to improve its availability, the absolute number of territories occupied would be higher and the population would increase. Changes in lifehistory parameters influence population persistence through the demographic potential of each species. For both eagles, the survival of territorial birds is the most important factor in determining the proportion of territories occupied. This is in accordance with other 
studies, which mentioned that adult survival rate is one of the most important factors influencing population growth rates in long-lived birds (Mertz 1971, Newton 1979, Lande 1988). Increments in the survival rates of territorial and non-territorial birds had the greatest effect on the demographic potential $(\mathrm{k})$ of Bonelli's eagle, while fecundity and survival rates during the dependence period were less relevant. For the golden eagle, however, the demographic potential was strongly affected by increments in the survival rates of territorial birds, fecundity and survival rates of fledging birds, being less important the survival rates of non-territorial birds. Productivity of the golden eagle population was intermediate when compared with others (range: $0.2-$ 1.6; Arroyo et al. 1990, Gil 1994, Watson 1997), probably as a result of the effects of parental age (Carrete et al. unpubl.). Reductions in productivity are often related to the entry of subadult birds, considered as low quality breeders, into the breeding population (Forslund and Pärt 1995, Cam and Monnat 2000, Espie et al. 2000, Sánchez-Zapata et al. 2000, Carrete et al. unpubl.). Bonelli's eagle productivity, however, was among the highest reported in the literature (range: 0-1.7; Arroyo et al. 1995, Real and Mañosa 1997), and this fact might explain why this parameter was less relevant for this species.

Non-territorial bird survivorship was the second parameter that should be improved to increase the proportion of territories occupied by Bonelli's eagles. Population viability is sensitive to the search pattern of dispersers because breeder replacement depends entirely on juvenile dispersal. In the model, the survival of nonterritorial birds was related to their search ability, m, which represents the mean number of searches that a disperser may employ to find a suitable unoccupied territory and which may be higher if dispersing birds live longer. Higher dispersal mortality results in fewer territories being searched for on average before a suitable unoccupied one is found or the disperser dies. Despite the importance of dispersal patterns in ecological systems (Wiens 1996), little is known about dispersal in most species. For Bonelli's eagles, although young birds have been wing-tagged and ringed to estimate pre-adult mortality (Real et al. 1996), little detailed information on dispersal behavior is available (Real and Mañosa 2001). However, it is known that pre-adults cross the boundaries of their local breeding population during dispersal (unpubl.), and so regional management must be considered in any attempt to protect this eagle. Our estimation of the survival rate of non-territorial birds for this species $\left(s_{n}=0.12\right)$ was similar than that obtained previously in Levante and Catalonia (Spain) and southern France (Real and Mañosa 1997), but it is important to consider that values obtained with this model cannot discriminate in an open population what fractions correspond to mortality or immigration from neighbor- ing populations. Non-territorial bird survival estimated in the study area for golden eagles was higher than that obtained for other large raptor species, such as the Spanish imperial eagle Aquila adalberti (Ferrer 1990), but similar to that estimated for non-territorial bearded vultures Gypaetus barbatus (Antor 2001). Considering that the proportion of sub-adult breeders present in our population (12\%, Sánchez-Zapata et al. 2000) was high when compared with others (Steenhof et al. 1983), we would expect to find that a short period of time elapses before birds enter the breeding population and that, consequently, there is a reduction in mortality during dispersal.

\section{General considerations on the model}

Results obtained from our models are somewhat optimistic as they do not take into consideration other factors, such as the Allée effect, migration between neighboring populations, conspecific attraction or stochastic fluctuations in life history parameters (Lande 1987, Carrete and Sánchez-Zapata, unpubl.). Moreover, given the long generation times and nesting site fidelity of these raptor species, the duration of the study could not ensure unbiased estimates of model parameters (proportions of suitable habitat and proportions of occupancy). However, our goals were not to make accurate long-term predictions; rather, we aimed to extend Lande's model by including interspecific competition, and to providing an example with conservation implications.

The use of mathematical models to analyze population viability has increased rapidly during the last decade and modeling efforts have focused on two goals: estimating extinction risk and identifying the best way to improve population growth. One of the most significant contributions of the present model is its ability to provide information on both of these factors by considering the interaction between two species that share food and nesting habitat. This is important in a number of contexts. First, it gives us a tool for detecting potential problems before they become critical; for example, to determine the potential impact of an increase in the population of one species on the other, or the effect of habitat modifications on the population dynamics of each species. Second, perturbation analysis, it could also guide field work to identify those lifehistory parameters for which the most precise estimates are needed. Finally, a scientifically rigorous and adaptive approach to wildlife management will require that management actions are conducted in a framework of quantitative predictions, treatment, evaluation, feedback and response. In this way, we could use this model to make a priori predictions about the most likely outcomes of management strategies and, thereby, eval- 
uate different alternatives before valuable resources have been invested.

Acknowledgements - Despite poor participation from the public organization responsible for protection of fauna in Murcia Region, this study was performed with the personal efforts of many people. We thank M. A. Sánchez, S. Eguía, P. Cortés, E. Pérez, J. Lacalle, M. León, J. E. Martínez, I. Pagán and the forestry wardens for their field assistance. J. L. Tella, J. Bascompte and J. Abellán gave valuable suggestions on the manuscript. This work was partially supported by an NSF grant to R. Lande. M. Carrete was supported by a predoctoral fellowship from the CONICET (Argentina) and a post-doctoral fellowship of the Fundación Séneca (Murcia, Spain).

\section{References}

Antor, R. J. 2001. Population status and conservation of the bearded vulture (Gypaetus barbatus) in the Pyrenees. - In: Raptor research foundation (ed.), 4th Eurasian Congress on Raptors. EBD-RRF, Sevilla, p. 8.

Arroyo, B., Ferreiro, E. and Garza, V. 1990. El Águila real (Aquila chrysaetos) en España. Censo, distribución, reproducción y conservación. - ICONA, Madrid.

Arroyo, B., Ferreiro, E. and Garza, V. 1995. El Âguila perdicera (Hieraaetus fasciatus) en España. Censo, distribución, reproducción y conservación. - ICONA, Madrid.

Begon, M., Harper, J. L. and Townsend, C. R. 1988. Ecología. Individuos, poblaciones y comunidades. - Ediciones Omega, Barcelona.

Burgman, M. A. 2000. Population viability analysis for bird conservation: prediction, heuristics, monitoring and psychology. - Emu 100: 347-353.

Cam, E. and Monnat, J. Y. 2000. Apparent inferiority of firsttime breeders in the kittiwake: the role of heterogeneity among age classes. - J. Anim. Ecol. 69: 380-394.

Carrete, M. 2002. The golden and the Bonelli's eagle in semiarid Mediterranean landscapes: distribution, territorial occupancy, breeding success and conservation. - $\mathrm{PhD}$ thesis, Univ. de Murcia, Murcia.

Carrete, M., Sánchez-Zapata, J. A. and Calvo, J. F. 2000. Breeding densities and habitat attributes of golden eagles in southeastern Spain. - J. Raptor Res. 34: 48-52.

Carrete, M., Sánchez-Zapata, J. A., Martínez, J. E. et al. 2002a. A territorial occupancy model of a Bonelli's eagle population: management implications. - Oryx 36: 349-356.

Carrete, M., Sánchez-Zapata, J. A., Martínez, J. E. et al. 2002b. Factors influencing the decline of a Bonelli's eagle Hieraaetus fasciatus population in SE Spain: demography, habitat or competition? - Biodiv. Conserv. 11: 975-985.

Carter, R. and Prince, S. D. 1981. Epidemic models used to explain biogeographical distribution limits. - Nature 293: 644-645.

Cramp, S. and Simmons, K. E. L. 1980. The birds of the western Palearctic. - Oxford Univ. Press.

del Hoyo, J., Elliot, A. and Sargatal, J. 1994. Handbook of the birds of the world. Vol II. New World vultures to guineafowl. - Lynx Edicions, Barcelona.

Díaz, M., Asensio, B. and Tellería, J. L. 1996. Aves Ibéricas. I. No Passeriformes. - Reyero, J.M., Madrid.

Doak, D. F. 1995. Source-sink models and the problem of habitat degradation: general models and applications to the Yellowstone grizzly. - Conserv. Biol. 9: 1370-1379.

Drechsler, M. and Wissel, C. 1997. Trade-offs between local and regional scale management of metapopulations. - Biol. Conserv. 83: $31-41$

Espie, R. H. M., Oliphant, L. W., James, P. C. et al. 2000. Agedependent breeding performance in Merlins (Falco columbarius). - Ecology 81: 3404-3415.
Fernández, C. and Insausti, J. A. 1990. Golden eagle takes up territories abandoned by Bonelli's eagle. - J. Raptor Res. 24: $124-125$

Ferrer, M. 1990. Dispersión juvenil de la población de águilas imperiales del Parque Nacional de Doñana. - PhD thesis. Univ. de Sevilla, Sevilla.

Forslund, P. and Pärt, T. 1995. Age and reproduction in birds: hypothesis and tests. - Trends Ecol. Evol. 10: 374-378.

Forsman, D. 1999. The raptors of Europe and middle East. A handbook of field identification. - T and AD Poyser.

Franklin, A. B., Anderson, D. R., Gutiérrez, R. J. et al. 2000. Climate, habitat quality and fitness in northern spotted owl populations in northwestern California. - Ecol. Monogr. 70: $539-590$.

Gil, J. M. 1994. Competencia entre el Águila real y el Águila perdicera en Granada. - Quercus, pp. 13-14.

Gil-Sánchez, J. M., Moleón, M., Otero, M. et al. 2004. A 9-year study of successful breeding in a Bonelli's eagle population in southern Spain: a basis for conservation. - Biol. Conserv. 118: 685-694.

Hanski, I. 1983. Coexistence of competitors in patchy environment. - Ecology 64: 493-500.

Hanski, I. 1999. Metapopulation ecology. - Oxford Univ. Press.

Hiraldo, F., Negro, J. J., Donázar, J. A. et al. 1996. A demographic model for a population of the endangered lesser kestrel in southern Spain. - J. Appl. Ecol. 33: 10851093.

Holt, R. D. and Keitt, T. H. 2000. Alternative causes for range limits: a metapopulation perspective. - Ecol. Lett. 3: 41-47.

Hutchinson, G. E. 1981. Introducción a la ecología de poblaciones. - Blume, Barcelona.

Ives, A. R. 1995. Measuring competition in a spatially heterogeneous environment. - Am. Nat. 146: 911-936.

Jordano, P. 1981. Relaciones interespecíficas y coexistencia entre el Águila real Aquila chrysaetos y el Águila perdicera Hieraaetus fasciatus en Sierra Morena Central. - Ardeola 28: $67-88$.

Lande, R. 1987. Extinction thresholds in demographic models of territorial populations. - Am. Nat. 130: 624-635.

Lande, R. 1988. Demographic models of the northern spotted owl (Strix occidentalis caurina). - Oecologia 75: 601-607.

Lande, R., Engen, S. and Sæther, B. E. 2003. Stochastic population dynamics in ecology and conservation. - Oxford Univ. Press.

Levins, R. 1969. Some demographic and genetic consequences of environmental heterogeneity for biological control. - Bull. Entomol. Soc. Am. 15: 237-240.

Little, R., Crowe, T. M. and Villacastín-Herrero, C. A. 1996. Conservation implications of long-term population trends, environmental correlates and predictive models for Namaqua sandgrouse Pterocles namaqua. - Biol. Conserv. 9: $857-868$

Martien, K. K., Taylor, B. L., Slooten, E. et al. 1999. A sensitivity analysis to guide research and management for Hector's dolphin. - Biol. Conserv. 90: 183-191.

McCarthy, M. A., Andelman, S. J. and Possingham, H. P. 2003. Reliability of relative predictions in population viability analysis. - Conserv. Biol. 17: 982-989.

Mertz, D. B. 1971. The mathematical demography of the California condor population. - Am. Nat. 105: 437-453.

Moilanen, A. and Hanski, I. 1995. Habitat destruction and coexistence of competitors in a spatially realistic metapopulation model. - J. Anim. Ecol. 64: 141-144.

Nee, S. and May, R. M. 1992. Dynamics of metapopulations: habitat destruction and competitive coexistence. - J. Anim. Ecol. 61: 37-40.

Newton, I. 1979. Population ecology of raptors. - T. and A. D. Poyser.

Noon, B. R. and McKelvey, K. S. 1996. A common framework for conservation planning: linking individual and metapopulation models. - In: McCullough, D. R. (ed.). Metapopulations and Wildlife Conservation. Island Press Washington. pp. 139-165. 
Real, J. and Mañosa, S. 1997. Demography and conservation of western European Bonelli's eagle Hieraaetus fasciatus populations. - Biol. Conserv. 79: 59-66.

Real, J. and Mañosa, S. 2001. Dispersal of juvenile and immature Bonelli's eagles in northeastern Spain. - J. Raptor Res. 35: 64-70.

Real, J., Mañosa, S., Cheylan, G. et al. 1996. A preliminary demographic approach to the Bonelli's eagle Hieraaetus fasciatus population decline in Spain and France. - In: Meyburg, B. U. and Chancellor, R. D. (eds). Eagle Studies. WWGBP, Berlin, London and Paris, pp. 523-528.

Real, J., Grande, J. M., Mañosa, S. et al. 2001. Geographic variation of the causes of death of Bonelli's eagle Hieraaetus fasciatus in Spain. - Bird Study 48: 221-228.

Rico, L., Sánchez-Zapata, J. A., Izquierdo, A. et al. 1999. Tendencias recientes en las poblaciones del Águila real Aquila chrysaetos y del Águila perdicera Hieraaetus fasciatus en la provincia de Valencia. - Ardeola 46: 235-238.

Rocamora, G. 1994. Bonelli's eagle Hieraaetus fasciatus. - In: Tucker, G. M. and Heatl, M. F. (eds), Birds in Europe, their conservation status. Bird Conservation Series, Cambridge, pp. $184-185$.

Sánchez-Zapata, J. A. 1997. Plan de Recuperación del Águila perdicera en la Región de Murcia, Consejería de Agricultura, Agua y Medio Ambiente. - Ambiental, S.L., Murcia.

Sánchez-Zapata, J. A., Sánchez, M. A., Calvo, J. F. et al. 1995. Ecología de las aves de presa de la Región de Murcia. - Univ. de Murcia, Murcia.

Sánchez-Zapata, J. A., Carrete, M., Calvo, J. F. et al. 2000. Age and breeding success of a golden eagle (Aquila chrysaetos) population in SE Spain. - Bird Study 47: 235-237.

Steenhof, K., Kochert, M. N. and Doremus, J. H. 1983. Nesting of subadult golden eagles in southwestern Idaho. - Auk 100: $743-747$.

Tella, J. L. 2001. Sex-ratio theory in conservation biology. - Trends Ecol. Evol. 16: 76-77.

Thomas, C. D. and Kunin, W. E. 1999. The spatial structure of populations. - J. Anim. Ecol. 68: 647-657.

Tilman, D. 1994. Competition and biodiversity in spatially structured habitats. - Ecology 75: 2-16.
Watson, J. 1997. The golden eagle. - T. and A.D. Poyser.

Wiens, J. A. 1996. Wildlife in patchy environments: metapopulations, mosaics and management. - In: McCullough, D. R. (ed). Metapopulations and wildlife conservation. Island Press Washington. pp. 53-84.

Wilson, W. G., Nisbet, R. M., Ross, A. H. et al. 1996. Abrupt population changes along smooth environmental gradients. - Bull. Math. Biol. 5: 907-922.

Woodworth, B. L. 1999. Modelling metapopulation dynamics of a songbird exposed to parasitism and predation and evaluating management options. - Conserv. Biol. 13: 67-76.

\section{Appendix}

Contrary to what happens with the Lotka-Volterra model, our two-species model does not allow the existence of unstable equilibrium where the outcome of competition depends on initial conditions. Here, we present the mathematical demonstration of this point.

Following Lande $(1987,1988)$, we denoted the stable single-species equilibria as $\mathrm{p}_{\mathrm{i}}^{1}=1-\left(1-\mathrm{k}_{\mathrm{i}}\right) / \mathrm{h}_{\mathrm{i}} \quad$ and $\mathrm{p}_{\mathrm{j}}^{1}=1-\left(1-\mathrm{k}_{\mathrm{j}}\right) / \mathrm{h}_{\mathrm{j}}$. From Eq. 8 the intercepts of the equilibrium isoclines with the axes are $I_{i i}=p_{i}^{1}, I_{j j}=p_{j}^{1}$, $I_{j i}=\left(h_{i} / h_{i j}\right) p_{i}^{1}$ and $I_{i j}=\left(h_{j} / h_{i j}\right) p_{j}^{1}$. The conditions for an unstable two-species equilibrium then becomes $p_{i}^{1}>\left(h_{j} /\right.$ $\left.\mathrm{h}_{\mathrm{ij}}\right) \mathrm{p}_{\mathrm{j}}^{1}$ and $\mathrm{p}_{\mathrm{j}}^{1}>\left(\mathrm{h}_{\mathrm{i}} / \mathrm{h}_{\mathrm{ij}}\right) \mathrm{p}_{\mathrm{i}}^{1}$. Multiplying both inequalities by $\mathrm{h}_{\mathrm{ij}}$ and adding them yields $\left(\mathrm{h}_{\mathrm{I}}-\mathrm{h}_{\mathrm{ij}}\right) \mathrm{p}_{\mathrm{i}}^{1}+\left(\mathrm{h}_{\mathrm{j}}-\mathrm{h}_{\mathrm{ij}}\right) \mathrm{p}_{\mathrm{j}}^{1}<0$. But all of the quantities on the left side must be nonnegative, so the last inequality is impossible. Therefore, an unstable two-species equilibrium can not occur. 